\title{
Some Observations on Spontaneous Sister Chromatid Exchange Frequencies and Cell Cycle Progression in Stimulated Lymphocytes of Patients With Different Malignancies
}

\author{
P. K. Gadhia, Salil Vaniawala* and Meonis Pithawala
}

Department of Biosciences, South Gujarat University, Surat 395 007, Gujarat, India *Shree Nath Pathology Laboratory, President Plaza, Ring Road, Surat, Gujarat, India

KEYWORDS Human lymphocytes; Malignancies; Spontaneous SCE rates; Cell cycle progression

\begin{abstract}
Total 23 patients with different malignancies viz. Ca. Lung (5), Ca. Uterine \& Cervix (5), Ca. Head \& Neck (5), Sarcomas (5) and Malignant Melanoma (3); were studied for spontaneous sister chromatid exchange frequencies (SCE) as well as cell cycle progression. All blood samples were collected prior to chemotherapy and/or radiotherapy to exclude the influence of these therapies, if any, on SCEs. Totally 15 healthy, age and sex matched individuals and belonging to the same socio-economic status, but no direct relatives of the patients were studied simultaneously as controls. The SCE rates, when compared to controls $(4.00 \pm 0.39)$ were found to be significantly high for patients with $\mathrm{Ca}$. lung $(9.42 \pm 1.20)$, malignant melanoma $(8.14 \pm 0.21)$, Ca. head \& neck $(6.85 \pm 0.89)$ as well as sarcomas $(6.29 \pm 0.79)$. However, no detectable difference was observed in the SCE rate for patients with Ca. uterine \& cervix $(5.02 \pm 0.88)$. Cell cycle proliferation and thereby replicative index was significantly elevated in patients with carcinoma of head \& neck as well as malignant melanoma. On the other hand, rest of the patients showed no much variation in cell cycle progression when compared to controls.
\end{abstract}

\section{INTRODUCTION}

The analysis of sister chromatid exchanges (SCEs) is a sensitive tool for evaluating DNA lesions of the kind that may lead to cancer development. Although the molecular mechanisms responsible for the production of SCEs are not still fully understood, yet SCE tests have been well accepted for studying carcinogenic and/or mutagenic potentials of chemical as well as physical agents (Privitera et al.1985). In human neoplasms SCE study has been used for various purposes and it may indicate a promising future for treatment monitoring (Sandberg 1980; Ohtsuru et al. 1980, 1982).

Retrospective and prospective reports on spontaneous SCE rates in lymphocytes of patients with different malignancies have so far yielded conflicting results. Few reports (Lukovie and Milson 1992; Xu 1993; Dhillon at al. 1996) have indicated higher spontaneous SCE rates in lymphocytes of cancer patients; while some (Brown et al. 1985; Adhvaryu et al. 1988; Nohutcu et al. 1991; Popp et al. 1994; Murthy et al. 1997) have indicated no changes in lymphocytic SCE rates for different cancer patients when compared to healthy controls. The results so far reported are therefore controversial.
Chromosome instability has long been suspected as a factor associated with neoplastic disorders. A relatively simple yet sensitive test that measures chromosome/DNA damage, is the quantitative analysis of SCE. This may signal changes associated with the pathologies of malignancy. The main aim of this study was therefore to determine whether peripheral lymphocytic SCE analysis of cancer patients has some potential to be of any value with respect to risk assessment, early detection and thereby possible prevention of cancer.

\section{MATERIALS AND METHODS}

Peripheral venous blood was collected aseptically in sodium heparinised vaccutainers from 15 controls and 23 patients with different malignancies viz. Ca. Lung (5), Ca. Uterine \& Cervix (5), Ca. Head \& Neck (5), Sarcomas (5) and Malignant Melanoma (3). These patients had not undergone any kind of chemotherapy and/or radiotherapy prior to collection of blood. Within 2-3 hrs of blood collection, the cultures were set up by adding $0.6 \mathrm{ml}$ of blood to $6 \mathrm{ml}$ HAM's F-10 medium (Sigma, USA), with 20\% autologus serum and $2 \%$ reconstituted Phytohemagglutin (PHA$\mathrm{M}$, Welcome Lab, UK). At $24 \mathrm{hr}$ of initiation of culture, $10 \mu \mathrm{g} / \mathrm{ml}$ of Bromodeoxyuridine (5-BrdU, 
Sigma, USA) was added. The cultures were protected from light to avoid BrdU degradation for all $72 \mathrm{hrs}$ of incubation. Colcimid (Serva, Germany) was added at a final concentration of 2 $\mathrm{mg} / \mathrm{ml}$ during last $2 \mathrm{hrs}$ of incubation, to stop mitosis.

Harvesting of the cultures was done by routine protocols of hypotonic treatment $(0.075$ $\mathrm{M} \mathrm{KCl}$ ) and washes of freshly prepared fixative 3:1 methanol-acetic acid. The slides were prepared by conventional air-dried method.

Sister chromatid differential staining was performed using routine procedure of Perry and Wolff(1974). Coverslips were mounted on slides stained in Hoechst 33258 (30 minutes at room temperature in darkness) and then exposed to fluorescence light for $24 \mathrm{hrs}$. The slides were then incubated in 2 X SSC (Standard Sodium Citrate) at $60^{\circ} \mathrm{C}$ for an hour. Finally they were stained with 3\% Giemsa (Qualigens, India).

Total of 100 well spread metaphases with clearly visible chromosomes were scored for each individual (control as well as cancer patient). In order to measure SCEs, we have examined a minimum of 30 second division $\left(\mathrm{M}_{2}\right)$ metaphases with least overlapping chromosomes.

Based on the differential staining categories, the number of cells in first division $\left(\mathrm{M}_{1}\right)$, second division $\left(\mathrm{M}_{2}\right)$ and the third division $\left(\mathrm{M}_{3}\right)$ stages were counted for cell cycle progression study. The replicative index (RI) was calculated employing following formula:

$\mathrm{RI}=\left(1 \mathrm{X} \% \mathrm{M}_{1}+2 \mathrm{X} \% \mathrm{M}_{2}+3 \mathrm{X} \% \mathrm{M}_{3}\right) 100$

For statistical analysis, two tailed Student's ' $t$ ' test was employed and a $P$ value of $5 \%$ or less was considered statistically significant as per the standard scientific practice.

\section{RESULTSAND DISCUSSION}

In the present study we have tried to analyze the different malignancies for their spontaneous base line SCE frequency rates, as well as cell cycle progression. Mean SCE/cell and RI for controls as well as various cancer patients have been presented in Table 1. The relative frequency in percentage of cells in $\mathrm{M}_{1}, \mathrm{M}_{2}$ and $\mathrm{M}_{3}$ division stages among various cancer patients and controls are shown in Figure 1. Sister chromatid exchanges among controls and cancer patients have been depicted in Figure 2, a and b, respectively.

Total of 15 healthy individuals who comprised the control study group had no history of familial malignancy and were not direct relatives, but belonged to the same socio-economic status of the cancer patients. The mean SCE level in them was found to be $4.00 \pm 0.39$, which served as a control guide-line for the malignant patients. Their RI was found to be 1.92. This background frequency of SCEs match very well with those reported for controls in our other studies (Gadhia and Joseph 1997; Joseph and Gadhia 2000).

Five patients with the carcinoma of lung (in the initial stage of disease) were selected for SCE examination. Significant increase $(\mathrm{P}<0.001)$ in mean SCE was found in these patients as compared to controls. However, they showed no significant difference in the RI.

The mean SCE/cell was $6.85 \pm 0.89$ for cancer of head \& neck patients which stood significantly high $(\mathrm{P}<0.05)$ as compared to controls. At the same time, RI was significantly increased among the patients with this malignancy for the number of $\mathrm{M}_{1}$ cells was decreased while that of $M_{3}$ was increased as compared to controls (Fig. 1). Our results are in agreement with those of Nohutcu et al. (1991) and Murthy et al. (1997) who have shown higher SCE rates in patients with carcinoma of head \& neck. Similar results have been suggested by Shankarnarayan et al. (1989). However, earlier Bazopoulou-Kyrkanidou et al. (1986) reported

Table 1: Sister chromatid exchanges and cell cycle progression in control and cancer patients

\begin{tabular}{|c|c|c|c|c|c|c|c|}
\hline & \multirow{2}{*}{$\begin{array}{c}\text { No. of } \\
\text { samples }\end{array}$} & \multirow{2}{*}{$\begin{array}{c}\text { No. of } \\
\text { cells } \\
\text { scored }\end{array}$} & \multicolumn{3}{|c|}{ Percentage of cells } & \multirow{2}{*}{$\begin{array}{c}\text { Mean } \\
\text { RI }\end{array}$} & \multirow{2}{*}{$\frac{\text { Mean }}{S C E / \text { cell } \pm S E}$} \\
\hline & & & $M_{1}$ & $M_{2}$ & $M_{3}$ & & \\
\hline Control & 15 & 1785 & 39 & 30 & 31 & 1.92 & $4.00 \pm 0.39$ \\
\hline Ca. Lung & 5 & 580 & 44 & 27 & 29 & 1.85 & $9.42 \pm 1.20^{\dagger}$ \\
\hline Ca. Uterine \& Cervix & 5 & 635 & 36 & 29 & 35 & 1.99 & $5.02 \pm 0.88$ \\
\hline Ca. Head \& Neck & 5 & 620 & 28 & 31 & 41 & $2.13 *$ & $6.85 \pm 0.89 *$ \\
\hline Sarcoma & 5 & 584 & 43 & 28 & 29 & 1.87 & $6.29 \pm 0.79 *$ \\
\hline Malignant Melanoma & 3 & 370 & 30 & 26 & 44 & $2.14 *$ & $8.14 \pm 0.21^{*}$ \\
\hline
\end{tabular}

* - Significant at $(\mathrm{P}<0.05)$ from the control $\ddagger$ - Significant at $(\mathrm{P}<0.01)$ from the control

$\dagger$ - Significant at $(\mathrm{P}<0.001)$ from the control 
normal baseline SCE levels in the patients with this malignancy.

One of the unusual findings of the present study was for 5 females with carcinoma of uterine $\&$ cervix, who showed normal SCE rates. Further in them RI was also normal with no remarkable difference. Majority of the results regarding baseline SCEs in Ca. uterine \& cervix are inconsistent. Xu (1993), Lukovie and Milsain (1992) and Dhillon et al. (1996) have reported increased SCE frequencies for this malignancy. While, Adhvaryu et al. (1985) have found normal baseline SCE in patients with $\mathrm{Ca}$. uterine \& cervix as compared to controls. Similarly, our results also

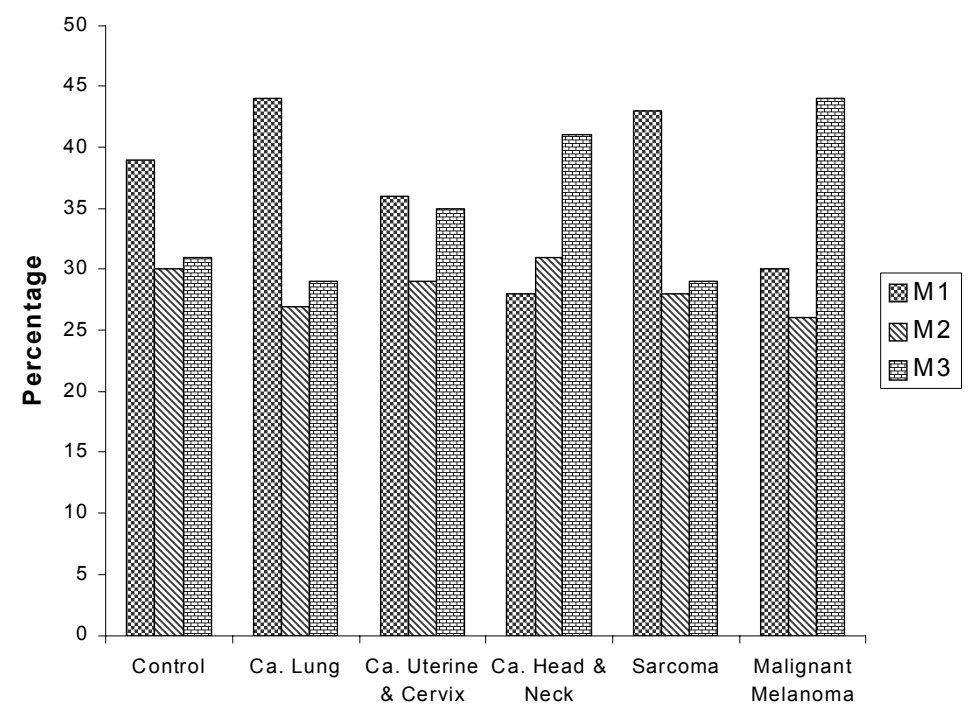

Fig. 1. Cell cycle proliferation in cancer patients

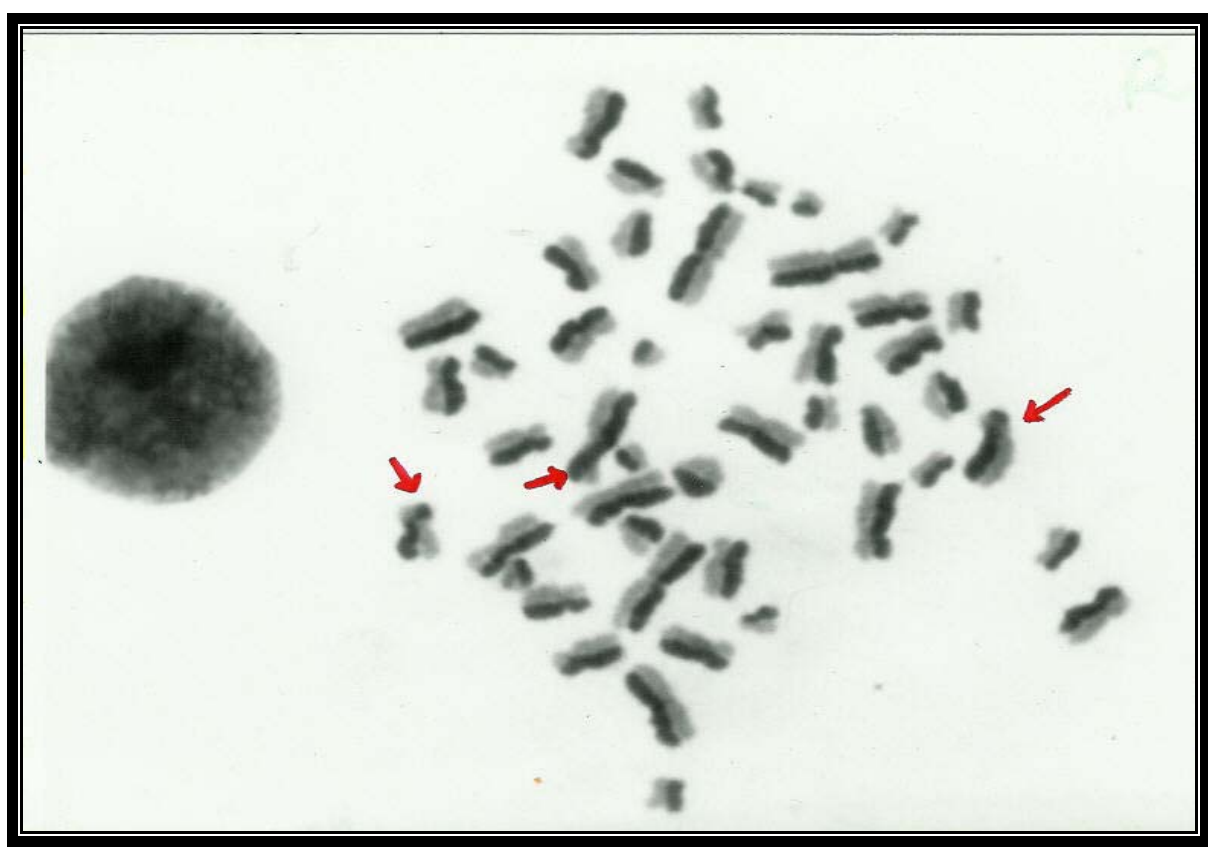

Fig. 2(a). Sister chromatid exchanges from control (X 7500) 


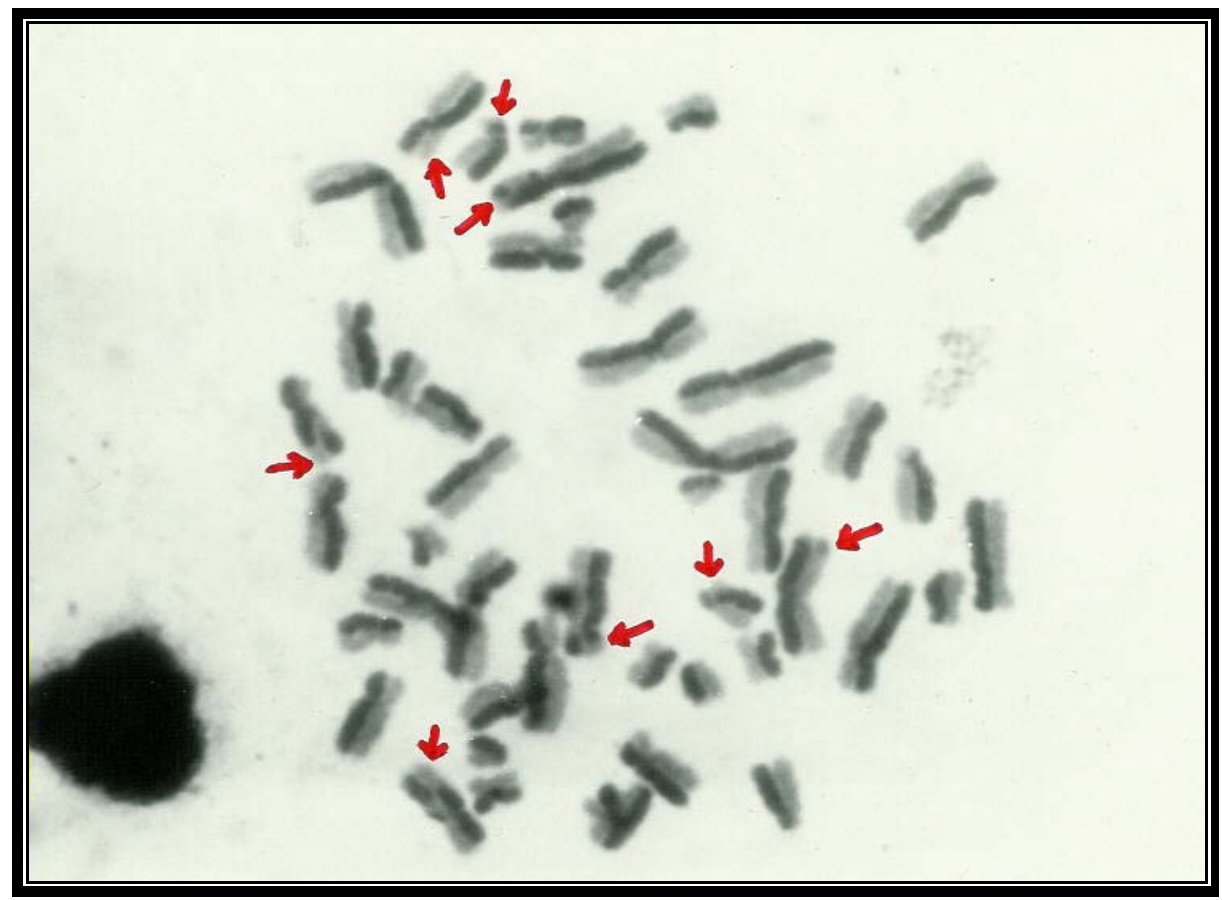

Fig. 2(b). Sister chromatid exchanges from Malignant Melanoma (X 7500)

failed to show higher baseline SCEs in patients with $\mathrm{Ca}$. uterine \& cervix.

As far as we are aware, there is paucity of information available for baseline SCE in sarcoma patients. We found significantly higher $(\mathrm{P}<0.05)$ SCE rates among sarcoma patients (3 Osteosarcoma and 2 rhabdomyosarcoma) as compared to controls. Still RI in these patients was nearly normal.

Finally in the present study, 3 patients with malignant melanoma also revealed significantly higher $(\mathrm{P}<0.01) \mathrm{SCE}$ rates. They also exhibited high RI.

Overall, results of the present study indicate higher spontaneous SCE rates for all malignancies studied except for carcinoma of uterine \& cervix; in comparison to controls. With regards to RI study patients with carcinomas of head \& neck and malignant melanoma showed increased RI, while the rest showed normal to near normal results.

\section{CONCLUSION}

Thus, looking to overall results it seems logical that SCE study has some significance while RI study is of little importance in identifying an individual's predisposal to malignancy. However, no totalitarian consideration be attributed to SCE in cancer diagnosis.

\section{ACKNOWLEDGEMENTS}

The authors wish to express their thanks to Mr. Dipesh Tamakuwla for kind help in the preparation of manuscript.

\section{REFERENCES}

Adhvaryu SG, Rawal UM, Patel JV, Patel DD, Balar DB 1988. Increased frequency of sister chromatid exchanges in lymphocytes of breast cancer patients. Int $J$ Cancer, 41(3): 394-398.

Adhvaryu SG, Vyas RC, Dave BJ, Trivedi AH, Parikh BN 1985. Spontaneous and induced sister chromatid exchange frequencies and cell cycle progression in lymphocytes of patients with carcinoma of the uterine cervix. Cancer Genet Cytogenet, 14: 6772.

Bazopoulou-Kyrkanidou E, Garas J, Angelopoulos AP 1986. Sister chromatid exchanges in lymphocytes of patients with oral carcinoma. Cancer Genet Cytogenet, 20 (1-2): 35-38

Brown T, Dawson AA, McDonald IA, Bullock I, Watt JL 1985. Chromosome damage and sister chromatid exchanges in lymphocyte cultures from patients with two primary cancers. Cancer Genet. Cytogenet, 17(1): $35-42$. 
Dhillon VS, Kier RS, Dhillon IK 1996. Chromosome instability and sister chromatid exchange (SCE) studies in patients with carcinoma of cervix uteri. Cancer Genet. Cytogenet, 18(1): 54-57.

Gadhia PK, Joseph S 1997. Sodium fluoride induced chromosome aberrations and sister chromatid exchange in cultured human lymphocytes. Fluoride, 30(3): $153-156$.

Joseph S, Gadhia PK 2000. Sister chromatid exchange frequency and chromosome aberrations in residents of fluoride endemic region of South Gujarat. Fluoride, 33(4): 192 - 196.

Lukovie L, Milsain J 1992. Sister chromatid exchanges in patients with carcinoma in situ of cervix uteri. Cancer Genet Cytogenet, 59(1) 84-85.

Murthy MK, Bhargava MK, Augustus M 1997. Sister chromatid exchange studies in oral cancer patients. Indian J Cancer, 34: 49-58.

Nohutcu RM, Emre S, Salizli M, Gursel B, Eratalay YK, Bosal N 1991. Sister chromatid exchange in lymphocytes of patients with cancer of the larynx. Am J Gtolaryngol, 12(2): 101-103.

Ohtsuru M, Ishil Y, Takai S, Higashi H, Kosaki G 1980. Sister chromatid exchanges in lymphocytes of cancer patients receiving Mitomycin-C treatment. Cancer Res, 40: 477-480.

Ohtsuru M, Ishil Y, Takai S, Kosaki G 1982. Sister chromatid exchanges in lymphocytes of a patient treated with cyclophosphamide and vincristine for non-Hodgkin's lymphoma. Gann, 73: 433-438.

Perry P, Wolff S 1974. New Giemsa method for the differential staining of sister chromatid. Nature, 251: 156-158.

Popp W, Wolf R, Vahrenholz C, Radike J, Schell C, Kraus R, Brauksiepe A, Norpoth K 1994. Sister chromatid exchange frequencies in lymphocytes of oral cancer patients seen to be influenced by drinking habits. Carcingenesis, 15 (8): 1603-1607.

Privitera E, Ghidoni A, Raimondi E, Rovini D, Teresa M, Illeni, Cascinelli N 1985. Sister chromatid exchange and proliferation pattern in stimulated lymphocytes of cutaneous malignant melanoma patients. Cancer Genet Cytogenet, 15: 37-45.

Sandberg AA, 1980. Some comments on sister chromatid exchange (SCE) in human neoplasia. Cancer Genet Cytogenet, 1: 197-206.

Sankaranarayanan R, Duffy SW, Day NE, Nair MK, Padmakumary C 1989. A case-control investigation of cancer of the oral tongue and the floor of the mouth in southern India. Int $J$ Cancer, 44(4): 617621.

$\mathrm{Xu}$ CF 1993. The frequencies of sister chromatid exchanges and chromosomal aberrations in the peripheral lymphocytes in patients with cervical carcinoma. Chung Hua Fu Chan Ko Tsa Chih, 28(8): 496-508. 